\title{
La pintura como forma de expresión en un dispositivo grupal infantil: Análisis de una experiencia en un contexto de salud pública
}

Painting as a form of expression in a children group device: Case analysis of an experience made in a context of public bealth

Daniela Cendoya Aburto ${ }^{1}$ Ignacio Yánez Castillo ${ }^{2}$

Resumen

El presente artículo se propone como un análisis de caso, cuyo objetivo es mostrar un dispositivo de intervención grupal infantil, llevado a cabo en un Centro Comunitario de Salud Mental Familiar (COSAM) de la Región Metropolitana, Santiago, Chile. Este dispositivo busca rescatar de manera relevante lo que para nosotros resulta ser el centro de la clínica infantil: el sufrimiento del niño. Dicha propuesta surge como respuesta a las falencias detectadas dentro de la Institución y que tienen relación con la forma en que se plantea actualmente el trabajo grupal en la infancia. En este sentido, se instaló un dispositivo grupal, basado en los planteamientos de la Asociación Uruguaya de Psicología y Psicopatología de la Expresión (A.U.P.P.E.), que contempló veinticinco sesiones y usó como metodología la creación libre de pinturas como forma de expresión de los integrantes del grupo.

Por medio del análisis de las creaciones pictóricas de uno de los miembros del grupo se busca dar cuenta tanto del proceso individual como del grupal, poniendo énfasis en el carácter comunicativo y terapéutico de la creación pictórica en un espacio seguro que brinde las posibilidades para la libre producción.

Palabras clave: Dispositivo grupal infantil, Pintura infantil, Proyección.

$1 \quad$ Psicóloga Universidad de Chile, Santiago de Chile, dcendoya@gmail.com

2 Psicólogo Universidad de Chile, Santiago de Chile, ignacioyanezcastillo@gmail.com 


\section{Abstract}

This paper consists of the analysis of a case study. Its objective is to propose and present a methodological device for group intervention with children. The research was undertaken in COSAM, Región Metropolitana, Santiago, Chile. This device seeks to expound the problems of what appears to be for us the center of therapeutic work with children: the suffering of the child; a response to the shortcomings, which were detected within the institution and its relation to the current approach of group work in childhood. In that sense, a method based on the proposals of Uruguayan Association of Psychology and Psychopathology of Expression (A.U.P.P.E), was implemented for the group work. Twenty five sessions were conducted, presenting a methodology of the free creation of paintings as a form of expression by the group members.

By analyzing the paintings of one of the members, seeks to account of the individual and group process. A special emphasis of the study is put on the communicative and therapeutical effects of the pictorial creation in a safe space that provides the posibility of a free production.

Key words: Child group device, Child painting, Projection.

Introducción y perspectiva teórica

En el presente artículo interesa dar cuenta de una experiencia grupal infantil, realizada en un Centro Comunitario de Salud Mental Familiar (COSAM) de la Región Metropolitana, que surgió a partir de la inquietud por cuestionar ciertas prácticas que se han venido llevando a cabo durante el último tiempo en dicha institución, las que de acuerdo con nuestro diagnóstico, ponen el acento en el aprendizaje de comportamientos -sobre todo disciplinares-, entrenamiento de habilidades sociales útiles para la adaptación al espacio escolar y familiar fundamentalmente, y no en lo que para nosotros resulta ser el centro de un trabajo terapéutico con infantes: el padecer o el sufrimiento del niño. 
El trabajo grupal infantil es una práctica que existe hace unos años en este COSAM y está inserto como actividad regular dentro del Programa Infanto-Juvenil. Las prestaciones que debe entregar el Centro para los nińos de la comuna se agrupan básicamente en dos programas, siendo la clasificación en uno u otro programa una cuestión más bien administrativa que no se traduce en diferencias tan sustanciales en cuanto al tipo de prestaciones que reciben los pacientes: el primero corresponde a lo que según el manual diagnóstico CIE 10 (Organización Mundial de la Salud [O.M.S], 1996) podrían ser categorizados dentro de los trastornos hipercinéticos y algunos casos de trastornos disociales; y el segundo, "comportamiento y emociones", incorpora una gama de diagnósticos pertenecientes a un trastorno comportamental o emocional. Se considera que no son parte de este programa los diagnósticos correspondientes, según CIE 10 (O.M.S, 1996), a trastornos generalizados del desarrollo, trastornos mentales orgánicos, esquizofrenia y retraso mental. Para ambos programas existe en el COSAM el denominado "taller grupal" como primera respuesta a la demanda de atención.

En este contexto, el taller grupal busca cumplir varias funciones: constituirse en la primera respuesta a la demanda familiar o escolar que entrega la institución, precisar un diagnóstico para evaluar la pertinencia de posteriores derivaciones, entrenar habilidades consideradas como disminuidas en los niños del taller y, por último, aunque no se declare explícitamente, cumple la función de ser una suerte de filtro de pacientes, puesto que muchas familias desertan de continuar el tratamiento en el COSAM durante este periodo. De esta manera se intenta no colapsar las atenciones individuales, debido a la gran cantidad de niños que son derivados al COSAM.

En otra cara del problema, surgen preguntas fundamentales de la clínica infantil: de dónde nace la demanda de atención para el niño y cómo a partir de esa demanda se puede comenzar un proceso terapéutico que abra paso a un posible padecer del niño. En esta dimensión nos encontramos nuevamente en un plano institucional en el que convergen, en la mayoría de los casos, el colegio y la familia, quienes declaran sentirse incómodos con el comportamiento del niño. Es así como el colegio o los padres 
determinan la necesidad de atención para el menor. El COSAM busca responder a dicha demanda, intentando eliminar los comportamientos que resultan disruptivos para lograr así una reinserción en el plano escolar y familiar.

En este contexto nos surge el interés de realizar un dispositivo distinto en el que, atendiendo la demanda familiar o escolar, se intente poner el acento no en el entrenamiento de habilidades específicas sino en generar condiciones para que en un contexto grupal surja la subjetividad del niño. Se busca así que éste, a través de su propia reelaboración, pueda traer su demanda terapéutica. Trabajando desde un enfoque grupal psicoanalítico se llega a la propuesta de reunir a un grupo de niños derivados al COSAM, que tuvieran entre 8 y 11 años de edad. La metodología a utilizar durante las sesiones sería la creación libre de pinturas con pinceles sobre hojas de papel, como forma de expresión, a partir del dispositivo propuesto por la A.U.P.P.E., en su libro Psicología de la Expresión (Carrasco \& Fernández, 1970).

Para el trabajo de análisis se considerarán fundamentalmente los planteamientos de M. Rodulfo (1992) en su libro El niño del dibujo. No es la pretensión de este artículo realizar una revisión teórica de los planteamientos de esta autora, sólo se señalan algunos puntos fundamentales que contribuirán a hacer más comprensible la exposición de la experiencia. Uno de los elementos principales que Rodulfo (1992) propone para el análisis del material pictográfico, y que nosotros rescatamos para nuestro trabajo, es considerar estas producciones en tanto secuencias pictóricas (o asociativas), más que como producciones aisladas, en la medida en que serán las repeticiones y transformaciones, como forma de acceso al material inconsciente, las que irán alumbrando un terreno que se presenta disperso y caótico en un comienzo.

En lo que respecta al marco de referencia teórico para comprender lo grupal, se utilizará a Garbarino, Freire y Mieres (1971) en Psicoanálisis Grupal de Niños y Adolescentes y a Fau (1964) en Grupos de Niños y Adolescentes como ejes centrales. Para este último, la formación del grupo de niños representa una fase esencial en la socialización, responde a una necesidad normal de apoyo en el combate que el niño libra para 
desprenderse de los lazos maternos. El niño aporta al grupo su dinamismo, construye y organiza lo que no habría construido ni organizado si hubiera vivido solo; en el grupo, el niño proyecta, transfiere y sublima.

El niño logra adaptarse al grupo porque ha superado convenientemente sus conflictos familiares; se ha desembarazado de su infantilismo haciéndose adaptable al grupo. Es así como la evolución de las relaciones del infante al interior del grupo va inseparablemente unida a la evolución de las relaciones que mantiene fuera de él (Fau, 1964).

Por otra parte, en cuanto al lugar del psicólogo, Garbarino et al. plantean que "corresponde a la coparticipación, de modo que la parte alienada del mundo infantil es traída a sesión y recuperada en la relación terapeuta-paciente" (1971, p. 27). Mediante la interpretación que verbaliza la aceptación de las fantasías infantiles encontramos el factor terapéutico más importante en el psicoanálisis grupal infantil. En éste el terapeuta ocupa una posición ambigua de niño o adolescente -por la regresión- y de adulto que recibe las ansiedades de alienación y las contiene (en su doble sentido de continente y límite). A través de las interpretaciones y del contexto establece la continuidad niño-adulto, permitiendo la integración del grupo y, por ende, la desalienación y la labor terapéutica.

Como tercer eje teórico se utilizarán los planteamientos de Winnicott referentes a la creación y a su relación con la constitución de la subjetividad. Winnicott (1971) entiende la creación en un sentido amplio, como un elemento primordial en el desarrollo de la persona a lo largo de su vida, como una cualidad del individuo que caracteriza su forma de relacionarse con el mundo exterior y cuyos orígenes se encuentran en los primeros intentos del niño por relacionarse con un mundo distinto a él.

Tanto el juego como el arte se encontrarían en una zona intermedia de experiencia. Estas manifestaciones constituyen para el autor la demostración más auténtica de la personalidad, ya que en ellas la persona se muestra creadora: "lo universal es el juego, y corresponde a la salud: facilita el crecimiento y por lo tanto esta última; conduce a relaciones de grupo; puede ser una forma de comunicación en psicoterapia” (Winnicott, 1971, p. 65). Así, se puede entender que el arte en los niños permite un lugar similar, cuando se propicia como un juego, un lugar en 
el cual es posible operar en la realidad y con objetos reales, hacer uso de la ilusión, la fantasía y el sueño. La pintura permite el acceso a emociones, deseos, fantasías, cuya expresión directa no está disponible.

El jugar del nińo le posibilita experienciar la realidad desde su propia lupa. En este sentido, el jugar para Winnicott (1971) se configura como una acción recíproca entre ambas realidades -tanto externa como interna-, lo que para este autor permite la transformación progresiva de la realidad psíquica, posibilitando, a su vez, la existencia del individuo.

\section{Metodología}

El taller grupal de pintura tuvo lugar en un COSAM de la Región Metropolitana, enmarcándose dentro del programa Infanto-Juvenil, por lo que se ajustó a las normativas y necesidades de dicha institución. Su duración fue de cuatro meses, realizándose dos sesiones semanales, de 45 minutos cada una.

\section{Formación del grupo}

Para seleccionar a los niños que asistieron al taller se determinó que, independiente del diagnóstico, los participantes debían compartir la presencia de dificultades de integración a grupos sociales, descartando existencia de psicosis o retardos graves. No nos pareció adecuado agrupar por cuadro patológico, ya que nos encontramos con que "podría crearse una estructura grupal demasiado rígida” (Garbarino et al., 1971, p. 51) en cuanto a las ansiedades y defensas, dificultando su elaboración por parte del grupo. Si bien hablar de dificultad de integración a lo social puede ser muy general y reconocemos múltiples manifestaciones y causales, no era nuestro fin reunir un grupo con conflictos homogéneos, sino poder recoger una problemática de importancia tanto para el niño como para la familia y el colegio. El segundo criterio consistió en agrupar a niños de edades similares, que compartieran cierto grado de desarrollo psicosexual. Y por último, procuramos mantener cierta paridad en la proporción entre los sexos, lo que permite la confrontación de ambos en el interior del grupo y el análisis de estos conflictos. 
Al finalizar este proceso de revisión de historiales clínicos se seleccionó a seis niños: dos mujeres y cuatro hombres, cuyas edades iban desde los 8 a los 12 años. A pesar de que el rango de edad fue más amplio que lo propuesto, nos pareció adecuado este cambio, por considerar que los integrantes cumplían con la condición de encontrarse en una fase psicosexual de desarrollo similar. Por otra parte, como características generales de los niños, los seis asistían regularmente al colegio, vivían con sus familias y pertenecían a un nivel socioeconómico medio-bajo.

Una vez seleccionados, se realizó una entrevista a cada uno, con sus padres o tutor, y después con el niño en privado. El objetivo de estas sesiones fue establecer un primer contacto tanto con el niño como con sus padres, conocer la situación actual del grupo familiar y las dificultades del niño.

\section{Los coordinadores}

La coordinación del grupo fue realizada por una pareja de psicólogos. Las ventajas de esta modalidad se verificaron durante la tarea. En la misma sesión era posible hacer el registro, entregar y reponer materiales, además de las funciones propias del proceso. Cabe señalar que la literatura da cuenta de que la formación de grupos infantiles con una pareja de coordinadores, en particular, con una pareja de ambos sexos, facilita la expresión de fantasías relacionadas con las imágenes parentales. Así como la transferencia y las ansiedades contratransferenciales son compartidas por ambos terapeutas (Garbarino et al., 1971). La principal función de los coordinadores fue la de posibilitar que los niños pintaran en forma libre y creativa, para lo cual el uso de la palabra tuvo como fin ayudar al niño a seguir su asociación en la pintura.

\section{El encuadre}

$\mathrm{Al}$ inicio de cada sesión los niños ingresaban a la sala junto con los coordinadores. La consigna inicial fue "pinten lo que quieran". Cada niño podía ocupar el lugar que quisiera, comenzando siempre con una hoja en blanco. Cuando un niño terminaba de pintar se ponía una nueva hoja, más allá de que el niño expresara su intención de seguir o no seguir pintando. 
Para el abordaje de las producciones gráficas se utilizaron como parte del marco de referencia los planteamientos de Dolto (s. f.) sintetizados por Mosquera:

“...Dejarse impresionar por lo gráfico, o sea observar el dibujo detenidamente, no sólo en sus aspectos más logrados sino en los borrones, tachones, transparencias, posibles similitudes entre grafías, etc. (...) todo aquello que se aparte de la corrección del proceso secundario. Preguntarse sobre lo que pueda recortarse como significante. (...) Para lo cual le pedimos al niño mismo que describa fragmentos en su dibujo. Pedir asociaciones, intentando que la pregunta sea esa intervención que facilite la deriva asociativa ('¿Qué sucede allí?'; ‘QQuiénes son esos personajes?'; 'Si estuvieras en ese dibujo, ¿dónde estarías?'), facilitando así la pesquisa del juego identificatorio. Si el niño espontáneamente deja el dibujo y se pone a hacer otro, no insistimos, ya que entendemos que ese dibujo le ha servido para decir algo que necesita seguir comunicándonos a través de otro gráfico, por lo que, entonces, seguimos su asociación” (citado en Mosquera, s.f., p. 6).

\section{Los materiales}

Se acondicionó una sala con seis puestos para pintar, que consistían en un cartón pegado a la muralla (para poner la hoja de papel) y junto a él, una silla. Esta disposición determinó que los niños pintaran de pie, mirando hacia la muralla, dándose la espalda unos con otros. La pintura era una mezcla de cola fría, agua y tierra de color; pintura que se caracteriza por su poca consistencia, dúctil y lavable. A cada niño se le entregaban dos pinceles, uno grueso y otro delgado, agua, un trapo para limpiar y una cubeta de hielos que servía de mezclador de pinturas. Los colores usados fueron: blanco, negro, rojo, azul, amarillo y verde; elegidos por ser colores básicos que los niños podían mezclar con facilidad. 
Análisis

Descripción y análisis del proceso de Manuel en el grupo

Por la gran cantidad de material producido en el taller se decidió privilegiar la exposición resumida relativa a uno de los integrantes del grupo (Manuel), intentando a través de él mostrar la experiencia grupal. De ningún modo tenemos la pretensión de dar cuenta de la totalidad del proceso de Manuel. El número de pinturas realizadas nos obligó a seleccionar ciertos cuadros que nos parecieron más representativos de las temáticas y que buscan evidenciar, al menos en parte, el trabajo psíquico realizado por Manuel. Tenemos presente que tal recorte implica un inevitable empobrecimiento de lo que fue la experiencia.

Otro elemento a tener presente y que va en desmedro de las aspiraciones de este análisis es la ambición de llevar a un texto escrito las circunstancias implicadas en la creación de las producciones gráficas. Como un intento por soslayar estas limitaciones recurriremos a la reproducción textual de diálogos generados durante las sesiones, junto con algunos de los dibujos realizados por Manuel.

\section{Antecedentes de Manuel}

Escogimos a Manuel, ya que fue quien asistió de forma más regular a las sesiones, creando un mayor número de producciones gráficas. En él pudimos observar de mejor manera los distintos cambios que fue expresando su pintura, desde los contenidos, formas, técnicas utilizadas, hasta cómo logramos percibir ciertos beneficios terapéuticos.

Manuel, a su ingreso al grupo, tenía 9 años de edad. Durante el proceso grupal cumplió 10 . Vive con su madre que trabaja todo el día, una media hermana de 18 años, su tío materno y su abuela, quien ha tenido un importante rol en su crianza, debido al trabajo de la madre. Su padre murió en un accidente cuando él tenía cerca de un año de vida. 
En cuanto a su historia escolar, Manuel no ha presentado problemas de rendimiento. De acuerdo con el relato de la madre, Manuel tuvo problemas en la adquisición del lenguaje. Su mala pronunciación dificultaba el entendimiento con el resto y esto lo frustraba bastante.

A los 5 años fue diagnosticado con Síndrome de Déficit Atencional (SDA), por lo que fue medicado con anfetaminas y derivado al COSAM, donde comienza un proceso psicoterapéutico de cinco meses, al término del cual recibió el alta. Por ese entonces la madre manifestaba que Manuel era un niño muy llorón, con problemas por su pronunciación y su mal genio, que ante una frustración reaccionaba con mucha rabia.

A los 9 años Manuel reingresa al COSAM, respondiendo a la inquietud de su profesora, quien manifestaba la "intolerancia a la frustración y conducta impulsiva, pataletas explosivas". En la entrevista de ingreso la madre refiere que Manuel está bien, pero no tiene muchos amigos. Se lleva bien con su profesora, aunque en ocasiones ha tenido reacciones muy agresivas o bien pataletas en donde llora y se enrabia.

Durante la entrevista de ingreso Manuel afirma que le gusta pintar, aunque no es muy bueno para eso, pero en general muestra una actitud positiva acerca de asistir a un grupo con otros nińos.

Durante las primeras sesiones se muestra ansioso en cuanto a la relación con otros niños y con la tarea de pintar. Al presentarse tartamudea un poco, se frota las manos y le cuesta mantener contacto visual.

Ante la consigna propuesta se ve preocupado de que la pintura le quede "bien" o "correcta", de realizar figuras coherentes, es decir, que representen algo conocido o consensuado y, en particular, preocupación por respetar las formas, no saliéndose de ellas. Impresiona aquí el intento por pintar de acuerdo a lo que se "podría esperar" de él. Busca crear un dibujo "adecuado" o "defendido".

Sin embargo, este intento de adecuación en su primer dibujo (Fig. 1) se verá truncado por no controlar que la pintura se salga de la figura, lo que lleva a Manuel a lanzar el pincel, para luego sentarse en el suelo muy enojado y con una respiración agitada. Él dirá: "la pintura se me mancha, empiezo a pintar y se me mancha todo". Si bien Manuel se frustró rápidamente con el fracaso, al señalarle que puede comenzar 
uno nuevo, acepta, pareciera que olvida el enojo y ahora, con cuidado, comienza a repetir el mismo dibujo. Ambos representan a un dinosaurio de cuerpo completo, con extremidades cortas para el tamaño de la figura, un hocico abierto, con dientes grandes, garras en patas y brazos. Por el borde de su cuerpo se visualizan púas verdes, impresiona como un animal feroz y temible, aunque rígido en su expresión.

Vemos aquí de qué manera Manuel intenta establecer una distancia con la pintura, por la vacilación al pintar y por su precaución al hacerlo. Se observa cómo la acción del proceso secundario se hace patente, poniéndose al servicio de la resistencia proveniente del Yo. Leemos la ansiedad inicial de Manuel en relación con el grupo y la tarea, como esa alerta de intentar que por medio de la pintura no se hagan presentes elementos propios rechazados por el Yo. En este sentido se ve sobrepasado, no pudiendo evitar la presencia de elementos del inconsciente, tal como ocurre en los actos fallidos. Pensamos entonces en el fenómeno de espejo descrito por Carrasco y Férnandez. Manuel es capaz de intuir cierto valor en dicha pintura sin poder precisar por qué, ante lo cual aparece el rechazo a su producción y a la tarea. Tal como señala este autor, en relación a este fenómeno, Manuel fue "invadido por un estado de desaliento con sentimientos de incapacidad, de vacío y de confusión” (Carrasco \& Fernández, 1970, p.14).

Una característica relevante de la técnica utilizada por Manuel es el hecho de que dibuja primero el contorno y luego rellena, lo que leemos como un indicio de un rasgo más bien obsesivo de estructurar su dibujo. Recurriendo a la separación que plantea Carrasco y Fernández (1970) en relación a los niños que guían más su dibujo por medio del color o de la línea, Manuel responde en sus primeras producciones claramente a una preocupación por la línea, lo que según estos autores se condice con niños, que "presentan dificultades en el establecimiento de relaciones interpersonales, tienen pocos amigos, además de ser por lo general temerosos y cautos" (p. 26-27).

Proponemos que una de las razones del cambio en la actitud de Manuel es el dispositivo instalado que permitió la construcción de un ambiente propicio para la expresión libre. Se podía hablar de los dibujos, pero éstos no eran cuestionados por su calidad formal o estética. 
Quizás ofrecer una nueva hoja fue un acierto, en el sentido que permitió la reincorporación a la tarea.

Avanzando en el proceso grupal, quisiéramos destacar una secuencia de pinturas realizada de la sexta a la novena sesión. Cuando Manuel llega a la sexta sesión se encuentra por primera vez sin la compañía de otros niños. En este momento Manuel pregunta: “'Por qué no habrá venido otro niño, tía? Comienza a desarrollar una serie de cinco dibujos -en una misma sesión- en los que se destacan los contenidos de soledad, sentimientos de abandono o vulnerabilidad. En la Figura 2 se muestra uno de ellos.

Parece evidente el uso simbólico en los dibujos de Manuel en relación a las temáticas antes señaladas, movilizadas por la situación de la sesión, pero para ir más allá en el análisis de este material, buscando sus particularidades y de qué manera se relaciona con las otras producciones, recurriremos a una secuencia de tres dibujos que empezará a desarrollar a partir de la sesión siguiente, en las que sí está acompañado por otros niños. En este momento comenzará a crear lo que él denomina "El Destructor", que tendrá sus versiones 1.0, 2.0 y 3.0 (Figura 3) como él mismo lo señala. Uno de los elementos que caracteriza a esta secuencia es que se trata del mismo robot que en cada nueva versión incorpora diferentes armas:

Manuel: Aaaah!!! Sí!!! (...) Terminé!!! Es un robot con más armas, quería que se viera temible.

Luego de terminar este segundo dibujo comenzó a hacer el tercer "Destructor", que quedó inconcluso por el fin de la sesión. Sin embargo, a la sesión siguiente, el primer dibujo que realiza Manuel al enfrentarse nuevamente a la hoja en blanco fue "El Destructor 3.0":

Manuel: Ya le puse un láser y una excavadora. Ya le puse tantas armas que no hay espacio para nada más...

Coordinador: No hay espacio para nada más que armas.

Miguel: Manuel, ponle una pistola.

Manuel: Es que esto ya está muy guerrerito... ya hice las armas de la otra vez. 
Miguel: No parecen armas sino cosas de música.

Manuel: No... Estos son misiles y rayos. Tío ¡cómo se ve? (pregunta al coordinador).

Coordinador: Manuel, ¿y con quién se puede juntar ese robot? Miguel: Con nadie, porque lo atacaria!!! Con otros robots!!!

Manuel: Claro, con la versión 1.0 y 2.0.

Manuel comienza a hacer rápidamente un nuevo dibujo (Fig. 4). No se preocupa por que los colores se corran un poco. Pareciera, más bien, por la velocidad con la que pinta, que quisiera mostrar algo prontamente.

Al terminar comienza un nuevo diálogo:

Manuel: Oye Miguel!!! ¿Te gusta mi oso?

En eso, Miguel comienza a reír y Manuel se le acerca con los pinceles amenazándole con pintarle bigotes en la cara. Miguel arranca corriendo por la sala y riendo. Se les recuerda que tienen que pintar sobre el papel, pero Manuel continúa persiguiendo a Miguel.

Miguel: Es que tu osito es ridículo. (Acercándose a Manuel).

Manuel: No te riai!!!!

Miguel: Tu dibujo se estropeó (señalándole a Manuel que la pintura se ha corrido por el exceso y el poco cuidado que tuvo).

Manuel saca la hoja y tira su pincel al piso. Luego de eso Miguel le pide disculpas, pero Manuel se queda en silencio.

Coordinador: Tal vez Manuel puede pintar lo que siente y después hablar sobre eso. (Luego de esta intervención Manuel comienza a pintar y Miguel vuelve a su lugar).

Miguel: Sí, creo que me quiere matar... (Al ver la horca que está dibujando). (Fig. 5).

Manuel: Miguel, ¿me perdonas? Me arrepentí.. 
Quisiéramos destacar primero el cambio drástico en el contenido que viene desarrollando Manuel, entre los dibujos de soledad y vulnerabilidad en la sesión anterior y los que realiza luego, nombrados como "El destructor". Pensamos que se pueden reunir estos dibujos en dos grandes aspectos que giran en torno a un mismo tema, la relación con el otro. Si nos centramos en la descripción de los dibujos de "El Destructor" vemos cómo el mismo robot va adquiriendo cada vez más armamentos hasta un punto en que, tal como dice Manuel: "Ya le puse tantas armas que no hay espacio para nada más". Esta necesidad de tanto armamento puede ser leída como la necesidad por defenderse de forma agresiva en su relación con el otro y el mundo, como un intento por mostrarse fuerte e invulnerable. Pero, ¿cuál sería esa necesidad de armarse y mostrarse tan agresivo ante el mundo? Manuel, al ser enfrentado a lo que proyecta en el papel en relación a la agresividad de "Los Destructores", responde haciendo un osito (Fig. 4). Es a este osito al que se debe cuidar con armas y robots. Incluso se observa cierto placer en Manuel al mostrar estos robots, pero al ser enfrentado con este contenido, sobre todo en su dimensión de relación con el otro, desmonta la armadura robótica para mostrar un aspecto tierno y vulnerable.

Cabe relevar la connotación que ha adquirido la pintura como forma de comunicación para Manuel, en tanto realiza el ejercicio de leer en sus dibujos aspectos que tienen que ver con su propia personalidad y la emplea como forma de comunicación con los otros niños. Va utilizando la pintura para poner en juego ciertas temáticas, en un asociar progresivamente más libre. Cuando Miguel se ríe del dibujo de Manuel, este último lee bien porqué lo hace. No se está riendo del osito en sí, del dibujo, sino de Manuel en tanto creador de ese osito. Manuel, de alguna manera, es ese osito.

Es como si este espacio de confianza para la libre expresión que se venía construyendo hubiera sufrido una fisura en el momento en que Miguel se burla de su dibujo. Sin embargo, lo que nos hace suponer que permitió a Manuel reintegrarse a la tarea de dibujar fue nuevamente el espacio grupal, donde encuentra la posibilidad de pintar en un nuevo dibujo la rabia o impotencia que siente. En ese espacio ha sido respetado en sus 
tiempos y sobre todo en sus producciones, recibiéndolas siempre como un material creado por él y que en esa medida hablaban de su persona.

Podemos constatar el deseo por las relaciones con sus pares en una posición fraterna, lo que nos hace pensar en los recursos que Manuel pudiera movilizar positivamente para lograrlo. Aunque también observamos una autopercepción de fragilidad yoica en este encontrarse solo o abandonado que tan prontamente aparece.

El conflicto está puesto, entonces, en un deseo por contactarse con el otro, pero que ante la posibilidad de hacerlo aparece la angustia, ya que le recuerda su propia fragilidad, a lo que reacciona intentando establecer una armadura hostil de defensa.

De alguna manera, en la secuencia de "Destructores", se sofoca todo ese deseo que pulsa por salir con una formación reactiva -el robot no necesita de nadie- pero la defensa utilizada es frágil al cuestionamiento y la creación del osito nos lo ilustra. Es como si hubiese sido descubierto y realizara un intento por mostrar su gran necesidad interior de reconocimiento por parte del otro. En esta situación, el grupo lo desorienta y lo angustia, porque le muestra y cuestiona sus contenidos, es como un “¿Qué hago ahora?”. Del osito se burlan y el robot ya no defiende.

Sesiones más adelante se da el siguiente diálogo (Fig. 6).

Miguel: ;Oye Manuel!

Manuel: ¿Qué?

Miguel: Eso parece como un pollo con armadura (en relación al dibujo de Manuel).

Manuel: ¿iQué?? No es lo que parece.

Miguel: En serio, parece como un pollo, como una armadura. Manuel: Es un caballero de la época medieval, tiene una espada.

Miguel: Pienso, no creo, pienso que es un pollo con una armadura y una espada.

Manuel reacciona molesto, se aísla del grupo y se sienta a mirar por la ventana. Se da aquí una situación similar a la ridiculización que hace 
Miguel del oso dibujado por Manuel. Este "pollo con armadura" nos vuelve a hacer pensar en un yo frágil que intenta establecer defensas rígidas para poder enfrentarse a otros como algo que no es: un "caballero medieval". Lo que destacamos de importancia y nuevo en la creación de Manuel es que en este dibujo del "caballero medieval" o pollo, él, por medio de la negación dice: "No es lo que parece". Reconoce en la interpretación de Miguel el grado de verdad necesario para suponer que se puede tratar de ambos contenidos, algo así como un pollo medieval, y esto es relevante en la medida en que vemos cómo, por primera vez en un solo cuadro, Manuel sintetiza su ambivalencia en relación a la forma en la que se percibe y se muestra al mundo.

Sesiones más adelante destacamos una serie de producciones que ilustran de qué manera la pintura en Manuel ha adquirido una categoría absolutamente distinta a la de un comienzo. En la Figura 7 mezcla todos los colores en el papel, pinta con los pinceles y luego con los dedos, llenando toda la hoja, realizando de esta manera una obra completamente abstracta. Es decir, en su pintura no se evidencia un interés por representar formas o estructuras definidas:

Miguel: Manuel... ¿Qué estás pintando?

Manuel: ¿Qué te importa?

Miguel: Ya poh... ¿Qué estás pintando? No pintaste nada, sólo llenaste la hoja.

Coordinadora: A lo mejor lo pintó todo.

Manuel: Es una pintura del pasado.

Miguel: ¿De la prehistoria?

Manuel: No, no de eso.

Resulta notable la evolución en la pintura de Manuel: la fuerte regresión que experimenta su pintura en términos formales se explica por el momento transferencial que atravesaba, apareciendo entonces como un intento radical por ubicarse en una posición infantil de exclusividad en relación a la coordinadora. La rabia que le genera el competir por un lugar protagónico al interior del grupo y el no ser validado en esta posición por 
la coordinadora lo frustra. Eso se ve reflejado notablemente en su dibujo. La descarga pulsional se realizó esta vez sobre el papel. En esta obra no se observan formas y casi no se pueden distinguir colores ni espacios sin pintar.

El llegar a este punto no ha sido fácil, Manuel ha debido lidiar con sus propias dificultades, con la pintura en cuanto técnica y con los cuestionamientos de sus compańeros. Sin embargo, tal evolución ha sido posible precisamente porque la pintura ha adquirido un nuevo estatuto, que poco tiene que ver con lo estético. Manuel ha comprobado cómo este pintar le permite expresarse, comunicar y, en particular, comenzar a elaborar la ansiedad que le produce esta relación con los otros y cómo gracias a la pintura ha podido sortear los conflictos sin que éstos le produjeran montos de angustia que le paralizaran o terminaran en reacciones impulsivas de frustración.

En las próximas sesiones Manuel continuará desarrollando dibujos abstractos (Fig. 8). No nos cuenta qué es lo que ha dibujado, pinta en silencio; además de los pinceles, utiliza sus dedos y sus manos, pareciera estar concentrado en su tarea. Lo interesante de estos dibujos es que aparecen después de haber atravesado todo un recorrido al interior del proceso grupal, que posibilita esta regresión. En este sentido nos recuerda la importancia técnica que plantea este dispositivo: considerar la producción pictórica siempre desde un punto de vista secuencial y no en unidades aisladas. Distinto hubiera sido si esta serie de dibujos de pura descarga Manuel la hubiera desarrollado en una primera sesión, ya que podría hacer pensar incluso en la posibilidad de una psicosis infantil u otro cuadro de gravedad considerable.

Cercanos a la finalización del proceso, Manuel comenzará a dar salida a esta regresión. Sus contenidos poco a poco irán adquiriendo nuevamente forma y orden, pero desde un lugar distinto, de mayor elaboración psíquica. Es así como realiza una pintura que consiste en rellenar rombos previamente delimitados con distintos colores (Fig. 9). En este dibujo vemos una búsqueda por comenzar a ordenar el material que surgió a partir de la secuencia anterior, en que ni la forma ni la distinción entre los colores existían. Pensamos que este movimiento fue posible 
gracias a que, por una parte, comienza a reaparecer la función yoica, estructurando en su dibujo los distintos elementos que tuvieron espacio en las últimas producciones, algo así como un intento por que adquirieran sentido. Por otra parte, el inminente fin del proceso grupal, que pudo actuar como un acelerador de ciertos procesos terapéuticos.

En la última secuencia de dibujos que revisaremos en el proceso de Manuel se abordarán los realizados en la última sesión. Esta serie está compuesta por tres dibujos que entregan una suerte de síntesis de las temáticas planteadas por él, posibilitando así una salida del proceso que nos hace pensar en los cambios vivenciados al interior del grupo en relación a su conflictiva psíquica.

Con respecto al primer dibujo de la última sesión (Fig. 10), al ser consultado por su producción, señalará: "Aah. Estaba pensando en poner todos los colores, de los más claros a los más oscuros”.

En este dibujo vemos nuevamente este intento por ordenar los colores como representantes de sus afectos, pero ahora ya no se produce esa inundación de pintura sobre la hoja que se había dado antes, ni tampoco colores delimitados por rombos negros. Esta vez, a través de círculos, realiza una secuencia con distintas tonalidades que hacen suponer una mayor distinción e integración de estos afectos a la esfera del yo, en la medida en que a través de la pintura, y motivado por el proceso grupal, se han hecho presentes en el plano de la conciencia, exigiéndole al yo dicha tramitación.

Con respecto al segundo dibujo que realiza en esta última sesión (Fig. 11) se hace más patente aún la necesidad de darle un cierre al proceso grupal y cómo ha logrado avanzar en la tramitación de su conflictiva psíquica:

Coordinador: ¿Qué pintaste?

Manuel: Es un tiranosaurio.

Coordinador: ¿Y lo verde?

Manuel: $M m m m$. No me acuerdo... es un tricerator.

Coordinador: ¿Y éste, es el mismo dibujo que hiciste la primera vez? 
¿Te acuerdas? (Fig. 1).

Manuel: Sí.

Coordinador: ¿Y qué tienen de diferente el primero con éste?

Manuel: Aah. Es que en ése se me cayeron gotas y quedó mal y éste quedó bien.

Coordinador: Pero éste también tiene gotas... A lo mejor, las gotas ya no importan.

En esta pintura se puede sintetizar lo que ha significado el grupo para Manuel: vemos cómo se reedita el primer dibujo correspondiente al dinosaurio, pero esta vez el dinosaurio está en compañía de otro: el tricerator. Además, el dinosaurio aparece como menos temible, no aparece un gran hocico con dientes a diferencia del primero. Manuel hace la distinción entre uno y otro como aquel que me quedó mal y éste que quedó bien. Aunque se lo atribuye a las gotas en el dibujo, es evidente cómo no es esto a lo que se refiere, es a otra cosa. Las gotas aparecen en este último dinosaurio y el sentimiento de fracaso y la conducta de lanzar los materiales lejos no aparece. Este "quedar bien" al que hace referencia Manuel tiene que ver con la posibilidad de haberle dado un curso a ciertas problemáticas vivenciadas en el espacio grupal y que se sintetizan en este nuevo dinosaurio al que le entrega, por una parte la compañía de otro, y por otra, se ubica él mismo en una posición mucho menos agresiva y más flexible.

El último dibujo realizado en esta secuencia final (Fig. 12), correspondió a una ballena fuera del agua.

El simbolismo nos parece claro. Corresponde a la salida del proceso vivenciado, sale del agua-grupo, poniéndole punto final a este proceso y lo hace llenando de gotitas su pintura, que forman parte del chorro característico que lanzan las ballenas al respirar, como si esas gotas que en el primer dibujo aparecieron a pesar suyo estropeando su obra (Fig. 1) hubieran encontrado su lugar en esta última pintura en el chorro que lanza esta ballena. 


\section{Conclusiones}

El análisis de los dibujos de Manuel y su participación en el proceso grupal nos ha dado luces para entender la conflictiva psíquica que se esconde tras las "conductas impulsivas y la intolerancia a la frustración", causantes de la preocupación de la profesora y la madre de Manuel. La problemática se relaciona principalmente con una fragilidad yoica que dificulta su desarrollo psíquico, al entorpecer una integración más armónica de sus mociones pulsionales, sobre todo en relación con la agresividad en el contacto con el otro y con el mundo. Existe un intento por mostrarse fuerte y omnipotente junto con un deseo de protección y contacto. Observamos entonces la añoranza por un espacio mítico materno de contención.

Es precisamente en el espacio grupal, con otros niños, en donde esta contención no siempre es posible, principalmente en una edad en donde la competencia y la rivalidad fraterna se hacen tan patentes y necesarias para la confirmación de la propia identidad. La defensa opera desde aquí como este fantaseo que vemos en los dibujos de Manuel con ser todopoderoso, armado e invulnerable, ya que la posibilidad de salir dańado es vivenciada como una consecuencia probable que genera altos montos de angustia. Sin embargo, estas defensas que a ratos toman rasgos obsesivos y rígidos por controlar el mundo externo e interno también llegan a ser vivenciadas con culpa ante la posibilidad percibida de poder dañar al otro. Podemos sintetizar desde aquí cómo esta fragilidad del yo está dada por la amenaza de fuertes montos de agresión y destrucción que desde el inconsciente lo exigen de forma constante, siendo en ocasiones proyectadas en el mundo externo, que es vivido muchas veces también como amenazante.

Creemos que a partir de esta lectura se puede ir aclarando cómo surge la demanda de tratamiento. Así también nos explicamos las fuertes reacciones de rabia, las pataletas y la angustia y podemos entender, además, las dificultades que presenta el niño en su integración a los grupos de pares. A pesar de éstas, existe en él un fuerte deseo de integración, lo que se corresponde con el deseo de ser grande -al que se refiriera Freud como aquel motor del juego infantil-, y de desembarazarse de los lazos maternos. 
Es a raíz de este intento que surgen las dificultades, intento que además le permite no paralizarse, constituyendo un importante recurso del aparato psíquico de Manuel. En esta tensión es donde creemos poder acercarnos al padecer del niño y a su propia demanda por tratamiento.

Nos atrevemos a formular como hipótesis que las dificultades de Manuel se relacionan con sus primeros ańos de vida, en el inicio del jugar y el uso de la ilusión como nos plantea Winnicott (1971), pensando en las dificultades emocionales de la madre para sostener su rol.

Consideramos que el uso de la pintura como creación libre ha sido beneficioso para Manuel, ya que mediante ella ha podido decirnos mucho más que con las palabras. La renovación constante de las temáticas de sus dibujos, las transformaciones en su forma de pintar, junto con el gradual aumento en sus producciones nos hablan de que existió un continuo asociar, cada vez más libre y así un progresivo avance de lo que fue el proceso terapéutico. Las pinturas pudieron ser jugadas como un espacio transicional, en el que no eran cuestionadas por su intención o realidad. Cada creación implicó un trabajo mediante el cual Manuel pudo ir logrando la integración y elaboración de deseos, angustias, sensaciones y sentimientos en la composición de su dibujo, generando algo nuevo y original, haciendo posible la comunicación.

El hecho de que esta actividad se realice en un espacio grupal también es clave en este sentido, ya que es precisamente en la integración a grupos sociales donde Manuel presentaba mayores dificultades, por lo que la tarea de pintar en compañía de otros niños le ofrece una nueva manera de enfrentar dichas problemáticas. El grupo como entidad se convierte en una fase esencial en el desarrollo del niño. Lo que la pintura permite en lo grupal es ser el espacio mediador, posibilitando la elaboración de las ansiedades que provoca la integración a grupos sociales. Es la pintura la que pone en juego distintas temáticas y conflictos y también abre paso a la palabra. De tal forma, al finalizar el proceso grupal nos encontramos con que uno de los factores comunes señalados por los padres fueron los cambios que los niños tuvieron con respecto a sus grupos sociales. Si bien en distintos grados y modalidades, éstos apuntan a una mayor integración ya sea en el ámbito familiar o en el escolar. 
Nos parece importante detenernos aquí en algunas reflexiones en torno al proceso grupal. Existieron dos dificultades que surgieron al interior del grupo, una de ellas fue la poca participación que tuvieron las niñas en este proceso y que se reflejó en el pronto abandono de una de ellas y, por otra parte, la poca regularidad en la asistencia de los niños al taller. Ambas incidieron negativamente en la continuidad del proceso, ya que provocó que algunos de ellos no pudieran completar un proceso más acabado. Así, podríamos decir, a grandes rasgos, que dos de los niños desertaron antes de la mitad del proceso y otros cuatro asistieron a más de la mitad de las sesiones. En estos últimos niños logramos apreciar de mejor manera un proceso en relación al trabajo con la pintura, aumentando progresivamente la cantidad de trabajos por sesión y pudiendo abordar distintas temáticas. Proponemos en este aspecto que la revisión de cómo son conformados los grupos de niños en cuanto a número de participantes, paridad de sexos, desarrollo psicosexual y diversidad de cuadros nosológicos, podría constituir una importante ventaja para el trabajo grupal, evitando así la alta deserción que existe en estos grupos y situaciones de alto estrés para los profesionales. Y, por sobre todo, mejora la efectividad de los objetivos propuestos al apostar por una mayor heterogeneidad entre los miembros del grupo.

Queremos destacar desde aquí las implicancias y proyecciones que tiene el trabajo grupal con niños en el contexto de salud pública mental, y en particular los alcances que permite este tipo de dispositivo, en donde ya sea la pintura, el modelado o el juego, la creación libre en definitiva, abre paso a la expresión y elaboración grupal, poniendo en el centro el padecer del niño. En primer lugar, en relación a las políticas públicas que determinan la clasificación de las prestaciones, nos parece que esta modalidad de trabajo se ajusta de buena manera, más allá de las falencias y vacíos que presentan las actuales normativas. En segundo lugar, la modalidad grupal permite responder de forma más eficiente a la alta demanda, pero además posicionarse como un espacio terapéutico real, ya que, como hemos visto, nos permite abordar problemáticas del niño, o bien detectar la existencia de problemáticas mayores relacionadas con patologías más graves y así orientar un tratamiento individual más 
extendido en el tiempo si es necesario. Junto con esto, las posibilidades reales de este tipo de trabajo, en cuanto a costos e instalaciones, nos parecen cada vez más posibles en virtud de los avances de la salud pública en nuestro país.

Por último, consideramos de suma relevancia el hecho de poder ampliar las formas de tratamiento y ayuda que podemos ofrecer a nuestros nińos, principalmente optando por modalidades que se alejen cada vez más del disciplinamiento y la corrección de conductas. Preguntarnos por el lugar del niño nos parece un deber ético en nuestra profesión, así como es un deber para el médico que recibe a un niño con dolor, calmarlo mediante un tratamiento o medicamento. Al dolor psíquico, al sufrimiento del niño, debemos poder ofrecerle espacios adecuados a su edad que permitan el juego y la creación y que le den la confianza para expresarnos aquello mediante lo cual podremos contribuir a la cura.

\section{Referencias}

Carrasco, J. \& Fernández, M. (1970). La pintura como instrumento técnico de la psicología aplicada. Asociación Uruguaya de Psicología y Psicopatología de la Expresión (ed.). Psicología de la expresión (pp. 21-29). Montevideo: A. U. P. P. E.

Fau, R. (1964). Grupos de niños y adolescentes. Barcelona: Luis Miracle S. A. Fernández, M. (1970). Cincuenta años de pintura. Asociación Uruguaya de Psicología y Psicopatología de la Expresión (ed.), Psicología de la expresión (pp. 9-19). Montevideo: A. U. P. P. E.

Garbarino, Freire \& Mieres. (1971). Psicoanálisis grupal de niños y adolescentes. Montevideo: Oficina del libro - aem.

Mosquera, L. (s. f.). Clase número 5: El dibujo de un niño en análisis como la representación de un sueño extemporáneo en la transferencia. En D. Soubiate (comp.). El grafismo y su relación con lo inconsciente. Su interés en la práctica psicoanalítica con niños. Obtenido el 30 de junio de 2008 desde: www.edupsi.com/grafismo.

Organización Mundial de la Salud (1996). Clasificación multiaxial de los trastornos psiquiátricos en niños y adolescentes CIE-10. Madrid: Médica Panamericana S. A. 
Rodulfo, M. (1992). El niño del dibujo: Estudio psicoanalítico del grafismo $y$ sus funciones en la construcción temprana del cuerpo. Buenos Aires: Paidós.

Winnicott, D. (1971). Realidad y juego. Barcelona: Gedisa.

Fecha de recepción: 03 de mayo de 2010.

Fecha de aceptación: 13 de julio de 2010.

\section{Anexo}

Fig. 1

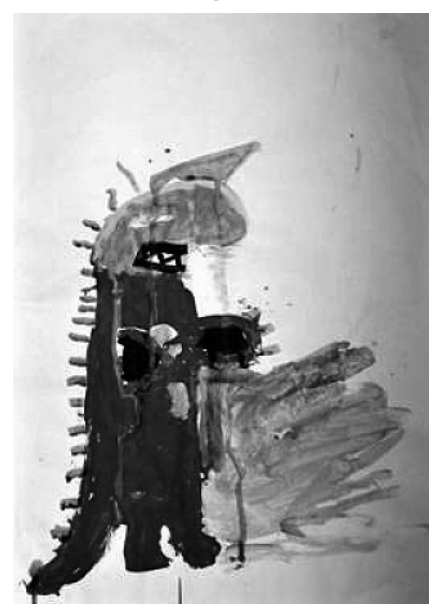

Fig. 3

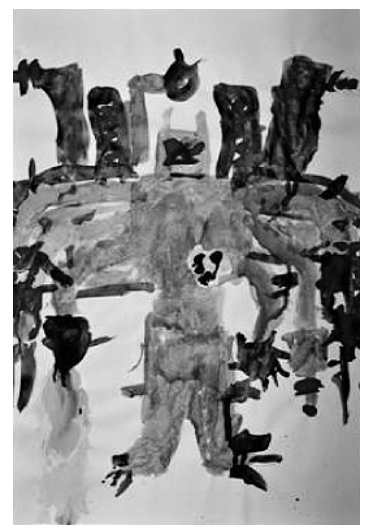

Fig. 2

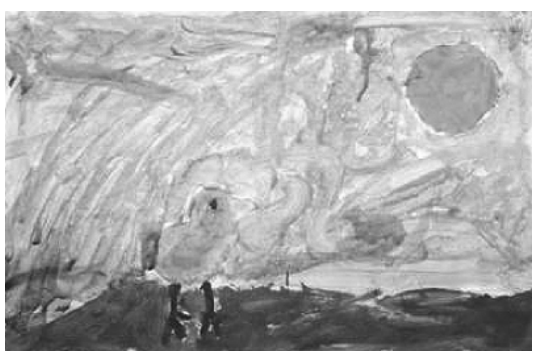

Fig. 4

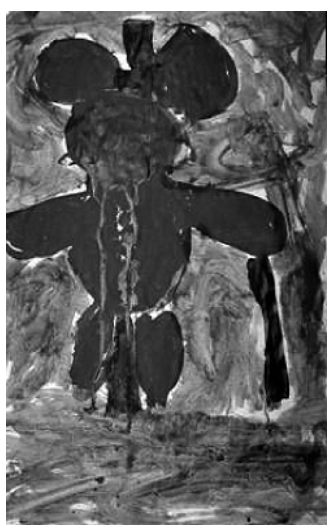


Fig. 5

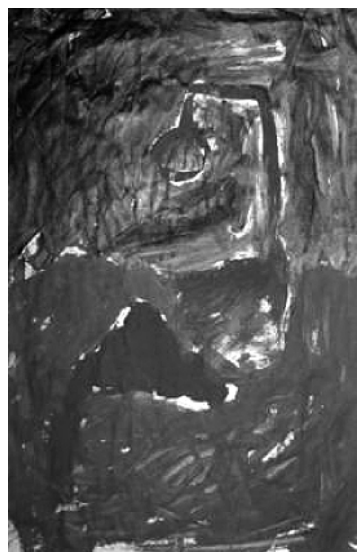

Fig. 7

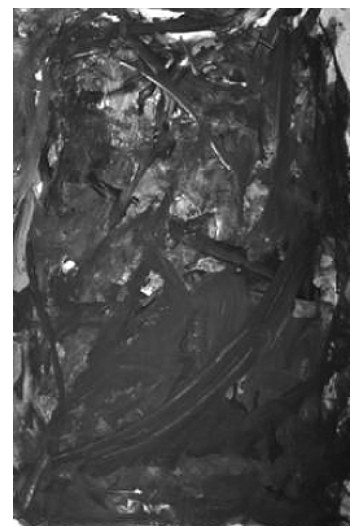

Fig. 9

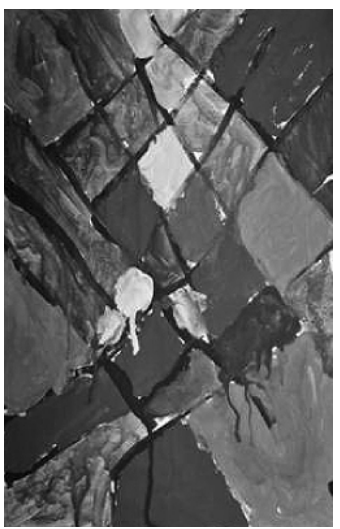

Fig. 6

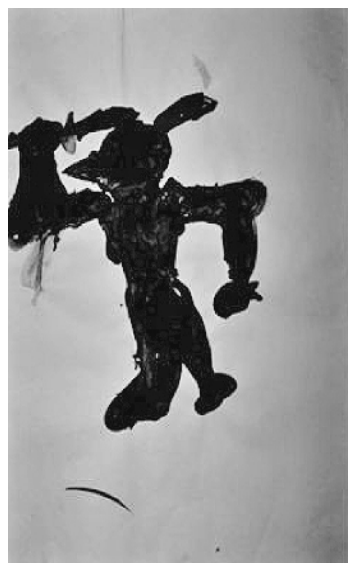

Fig. 8

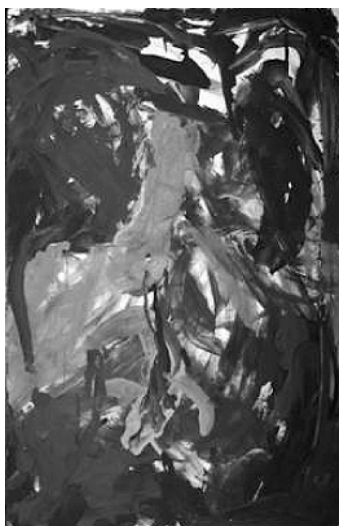

Fig. 10

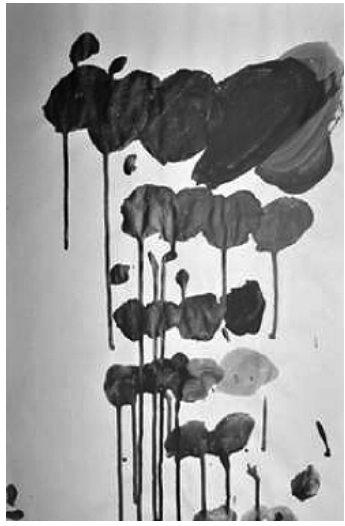


Fig. 11

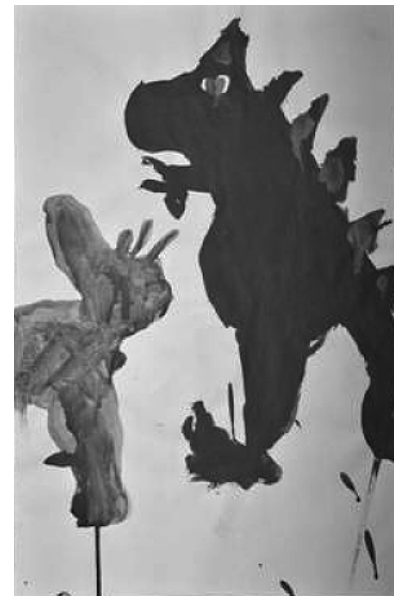

Fig. 12

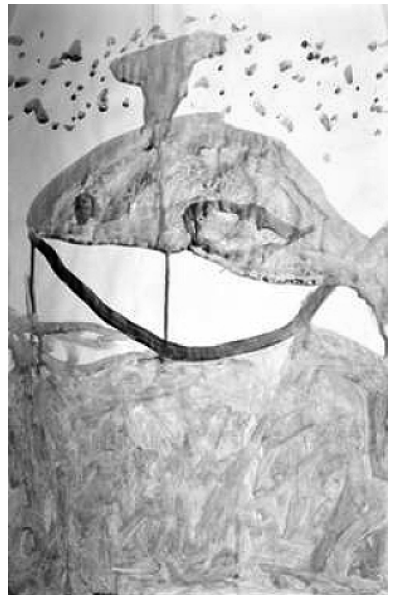

